Submitted to:

CEC/ICMC 2003 Conference

Anchorage, Alaska

September 22-26, 2003

\title{
COMPUTATIONAL SIMULATION OF \\ REFRIGERATION PROCESS FOR BEPCII SUPERCONDUCTING FACILITIES
}

\author{
L. WANG ${ }^{1}$, L.X. JIA ${ }^{2}$, H.P. DU ${ }^{1}$, G.D.Yang ${ }^{1}$ \\ ${ }^{1}$ Institute of Cryogenics and Superconductivity \\ Technology, Harbin Institute of Technology, \\ Harbin, 150001, CHINA \\ ${ }^{2}$ Brookhaven National Laboratory, Upton, \\ New York, 11973, USA
}

\begin{abstract}
The main challenge to build the cryogenic system for the Beijing Electron-Positron Collider Upgrade is to accommodate the strong differences among three types of superconducting devices with regard to their structure, location, as well as the cryogenic operating requirement. Three kinds of cooling methods are applied in the overall cryogenic system, saturated liquid helium cooling for the SRF cavities, single-phase helium cooling for the SCQ magnets, and two-phase helium cooling for the SSM solenoid. The optimization for the BEPCII cryogenic system was carried out by using a large-scale computational simulation package. This paper presents thermal parameters and numerical analyses for the BEPCII cryogenic system.
\end{abstract}

\section{INTRODUCTION}

In order to support the operation of three superconducting devices in BEPCII upgrade, a cryo-plant of $1.0 \mathrm{~kW}$ at $4.5 \mathrm{~K}$ is under design, which is composed of two refrigerator systems with each capacity of $500 \mathrm{~W}$ at $4.5 \mathrm{~K}[1]$. The cryogenic characteristics of the BEPCII superconducting facilities, including the superconducting RF (SRF or SCC) cavities, the superconducting quadrupole (SCQ) magnets and the superconducting detector 
(SSM) solenoid magnet were discussed in a paper published in ICEC19[2]. The SRF cavities are a pair of $500 \mathrm{MHz}$ single-cell niobium cavities residing inside a liquid helium vessel of around 300 liters. The SCQ magnets are a pair of iron-free, non-collared, multi-coil magnets with active shielding for the micro-beta focusing at the interaction region of the collider rings. The SSM magnet has a coil of $1.5 \mathrm{~m}$ in radius and of around $3.9 \mathrm{~m}$ in length and provides a magnet field of $1.0 \mathrm{~T}$. Correspondingly, three types of cooling methods are applied in the BEPCII cryogenic system[1,3], saturated liquid helium cooling for the SRF cavities, single-phase helium cooling for the SCQ magnets, and two-phase helium cooling for the SSM solenoid.

The engineering design of the BEPCII cryogenic system is being carried out by the Institute of Cryogenics and Superconductivity Technology at Harbin Institute of Technology. This paper presents the results of the static processing simulation for the three superconducting facilities cooling. The thermal operating parameters such as pressure, temperature, mass flow rate, enthalpy and fluid quality have been obtained for the BEPCII cryogenic system.

\section{COOLING SYSTEM FOR SCQ AND SSM MAGNETS}

\section{Cryogenic System Modeling}

FIGURE 1 shows the layout of BEPCII cryogenic system under design. One of the cold boxes of the two $500 \mathrm{~W}$ refrigerators is for two SRF cavities at the second collision hall and the other is for two SCQ magnets and one SSM magnet at the first collision hall. The helium compressor systems with their cooling-water systems, instrument air compressor system and various gas tanks are located in or around the cryogenic hall to be built. The cooling system for SCQ and SSM magnets mainly consists of the cold box, one liquid helium dewar of 1000 liter with one distribution valve box positioned on its top and one subcooler residing in it, two control valve boxes for two SCQ magnets, one control valve box for SSM solenoid, control system, and cryogenic transfer lines among the cold box, the subcooler, the distribution valve box and the control valve boxes for magnets.

The flow sheet for the simulation of the cryogenic system is given in FIGURE 2.

TABLE 1 lists the estimated heat loads of the SCQ and SSM magnets at $4.5 \mathrm{~K}$ [1] used for the simulation. The helium flow at 13 bara and $5.26 \mathrm{~K}$ from the cold box goes through the $\mathrm{J}-\mathrm{T} 1$ valve. The pressure of the flow drops to $2.7 \mathrm{bar}$ and its temperature lowers down to around $5 \mathrm{~K}$. The supercritical flow is then cooled through the sub-cooler immersed in the liquid helium at 1.2 bar and $4.4 \mathrm{~K}$. By the distribution valve box, two of the branches go to cool the SCQ magnets, and another one is further throttled to 1.25 bar and $4.43 \mathrm{~K}$ by the $\mathrm{J}-\mathrm{T} 2$ valve and to cool the SSM at two-phase condition. The return helium flow from the magnets is combined in the distribution valve box, goes through the $1000 \mathrm{~L}$ dewar, and back to the cold end of the cold box. The pressure drop along the cooling system is neglected in the simulation, and the operating temperature of the SCQ is kept lower than $4.8 \mathrm{~K}$. 


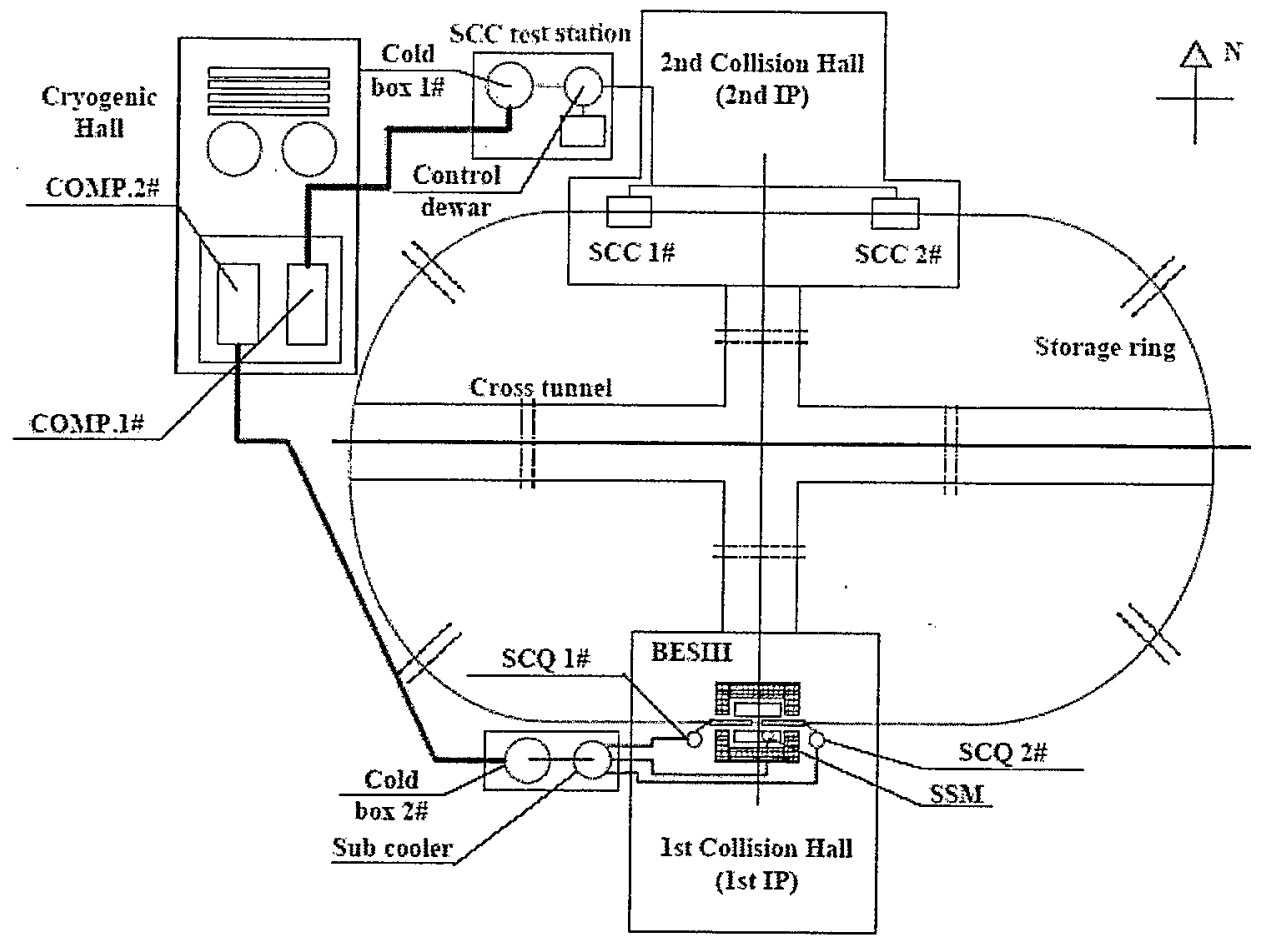

FIGURE 1. Layout of the BEPCII cryogenic system

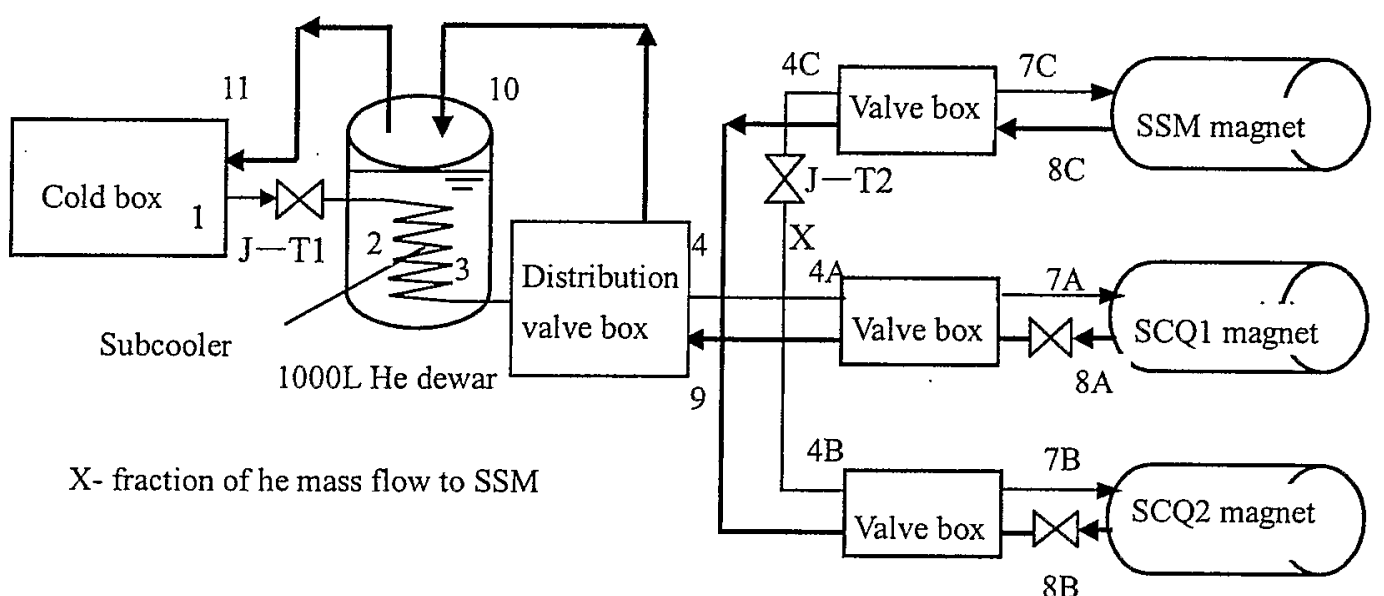

FIGURE 2. Numerical model of the cooling system for SCQ and SSM magnets

TABLE 1. Estimated heat Load of the SCQ and SSM Magnets at 4.5K[1]

\begin{tabular}{lccc}
\hline SCQ cryostat & $2 \times 7 \mathrm{~W}$ & SSM cryostat & $40 \mathrm{~W}$ \\
SCQ control valve box & $2 \times 10 \mathrm{~W}$ & SSM control valve box & $10 \mathrm{~W}$ \\
LHe dewar and heater & & $25 \mathrm{~W}$ & \\
Cryogenic transfer lines & $12 \mathrm{~W}$ & \\
SCQ current leads & $10 \mathrm{~W}$ (no power) & SSM current leads & $0.2 \mathrm{~g} / \mathrm{s}$ \\
& $0.12 \mathrm{~g} / \mathrm{s}$ (operation) & & \\
Others & $2 \mathrm{~W}$ & Eddy current loss & $5 \mathrm{~W}$ \\
\hline
\end{tabular}




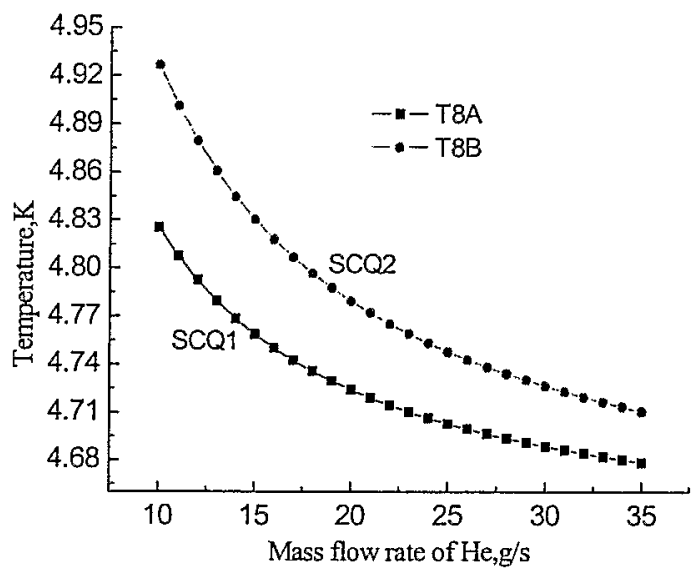

FIGURE 3. Relation of mass flow rate and outlet temperature of SCQ cooling passage

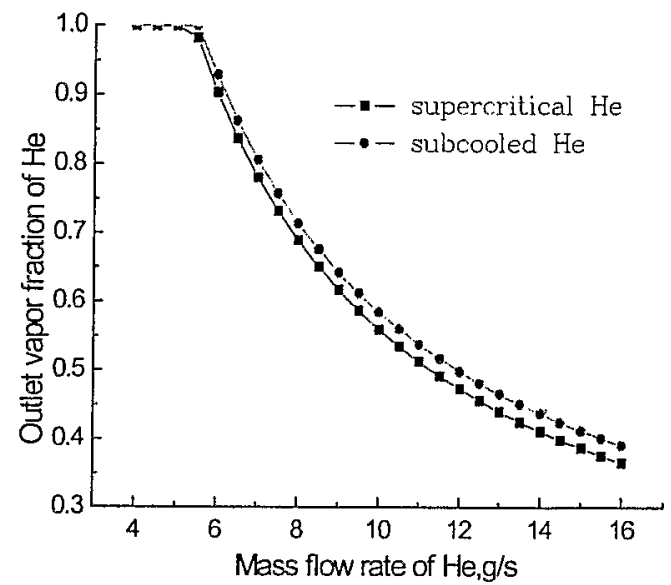

FIGURE 4. Mass flow rate vs vapor fraction at the outlet of SSM cooling passage

TABLE 2. Operating parameters of the magnets during normal operation

\begin{tabular}{lccccccc}
\hline & 1 & 2 & 3 & $4 \mathrm{~A}$ & $4 \mathrm{~B}$ & $4 \mathrm{C}$ & $7 \mathrm{~A}$ \\
$\mathrm{P}($ bar $)$ & 13.0 & 2.6950 & 2.6950 & 2.6785 & 2.6750 & 2.6785 & 2.6784 \\
$\mathrm{~T}(\mathrm{~K})$ & 5.26 & 5.08 & 4.60 & 4.64 & 4.70 & 4.67 & 4.70 \\
$\mathrm{~m}(\mathrm{~g} / \mathrm{s})$ & 36.03 & 36.03 & 36.03 & 12.0 & 18.38 & 5.66 & 12.0 \\
Vapor fraction & 1 & 0 & 0 & & 0 & 0 & 0 \\
& $7 \mathrm{~B}$ & $7 \mathrm{C}$ & $8 \mathrm{~A}$ & $8 \mathrm{~B}$ & $8 \mathrm{C}$ & 10 & \\
$\mathrm{P}($ bar) & 2.674 & 1.25 & 2.6782 & 2.6740 & 1.216 & 1.201 & \\
$\mathrm{~T}(\mathrm{~K})$ & 4.74 & 4.438 & 4.80 & 4.80 & 4.407 & 4.39 & \\
$\mathrm{~m}(\mathrm{~g} / \mathrm{s})$ & 18.38 & 5.66 & 12.0 & 18.38 & 5.66 & 35.59 & \\
Vapor fraction & 0 & 0.12 & 0 & 0 & 0.895 & 0.31 & \\
\hline
\end{tabular}

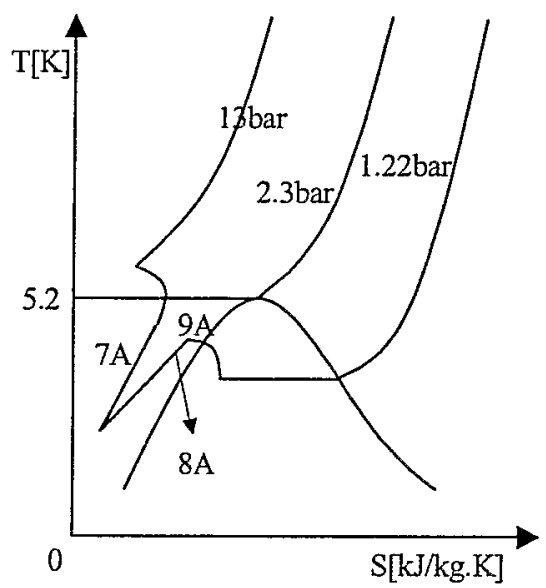

FIGURE 5a. T-s diagram for the SCQ magnet

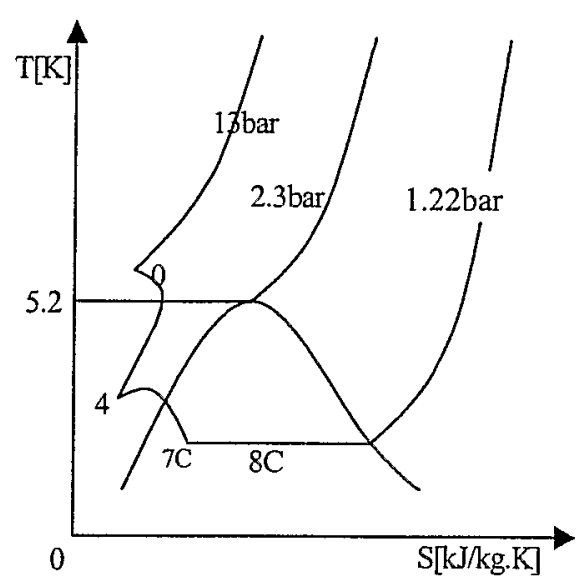

FIGURE 5b. T-s diagram for the SSM magnet 
FIGURE 3 indicates the change of the outlet temperature of return helium from the magnets with the mass flow rate of helium required by the SCQ magnets for a fixed subcooler outlet temperature of $4.6 \mathrm{~K}$. The difference of mass flow rate for the SCQ1 and $\mathrm{SCQ} 2$ is due to the different length of cryogenic transfer lines to them. In order to keep the outlet temperature to be lower than $4.8 \mathrm{~K}$, the required mass flow rate should be at least of $12 \mathrm{~g} / \mathrm{s}$ for SCQ1, and $18 \mathrm{~g} / \mathrm{s}$ for SCQ2.

The lines in FIGURE 4 labeled by solid circle and rectangular represent the relation between the mass flow rate of two-phase helium flow required by the SSM cooling and the vapor fraction at the outlet of SSM cooling passage, respectively when the SCQ magnets are cooled by the subcooled liquid helium at 1.8 bar and the supercritical helium at $2.7 \mathrm{bar}$. For both cases, the outlet temperature of the subcooler is $4.6 \mathrm{~K}$. The minimal mass flow rate of helium needed for the SSM is $5.6 \mathrm{~g} / \mathrm{s}$ while using supercritical helium to cool the SCQ magnets, which is smaller than that by using the subcooled liquid helium to cool the SCQ magnets. The operating parameters of the magnets during normal operation at the first collision hall are listed in TABLE 2. The T-S diagrams are obtained in FIGURE 5.

\section{COOLING SYSTEM FOR SRF CAVITIES}

\section{Cryogenic System Modeling}

The cooling system for SRF cavities mainly consists of the cold box, one 2000 liter liquid helium dewar, one distribution valve box for three SRF cavities including one test station, control system, cryogenic transfer lines among the cold box, $2000 \mathrm{~L}$ dewar, the distribution valve box and SRF cavities.

The flow sheet for the simulation of the cryogenic system is given in FIGURE 6.

TABLE 3 lists the estimated heat load of the cryogenic system for the SRF cavities[1]. The two-phase helium flow from the JT valve at about 1.2 bar and $4.4 \mathrm{~K}$ is separated in $2000 \mathrm{~L}$

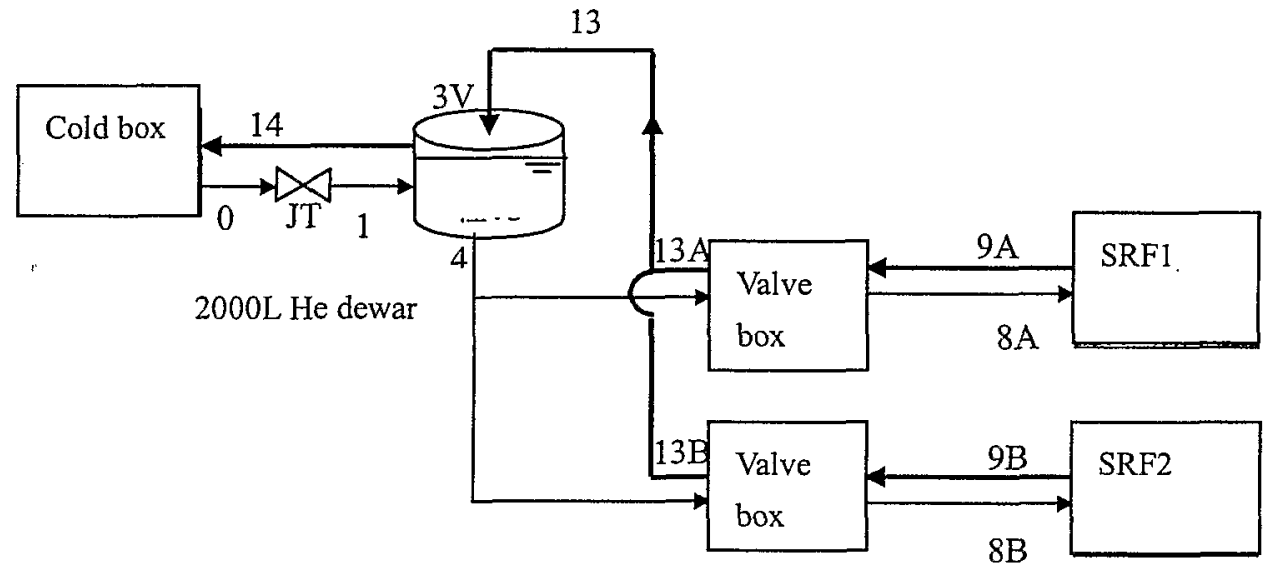

FIGURE 6. Numerical model of the cooling system for SRF cavities 
dewar. The liquid helium is sent to two SRF cavities, and the vapor is back to the cold end of the cold box combined with the gaseous return helium from the SRF cavities.

\section{Results and Analyses}

The minimal mass flow rates of helium required only for SRF1 and SRF2 are $7.0 \mathrm{~g} / \mathrm{s}$ and $7.9 \mathrm{~g} / \mathrm{s}$ at $1.22 \mathrm{bar}$, respectively. However, considering the heat load of the dewar, the distribution valve box and the cryogenic transfer lines, the total mass flow rate required for the cooling system is $27.1 \mathrm{~g} / \mathrm{s}$ including the coupler cooling. Because the return vapor helium flow from the cavities should adsorb the heat leak incurred along the cryogenic transfer lines and valve boxes from the outlet of the SRF cavities to the $2000 \mathrm{~L}$ dewar, its temperature increases before back into the dewar. This gives rise to the more loss of liquid helium in the dewar. FIGURE 7 shows the variation of the temperature of gaseous helium at the inlet of the dewar with the total mass flow rate needed for the cavities' cooling system, and FIGURE 8 gives the additional needed helium due to the high inlet temperature of gaseous helium to the dewar. From FIGURE 7, the total mass flow rate is about $27.1 \mathrm{~g} / \mathrm{s}$ in order to keep the temperature at around $4.4 \mathrm{~K}$. From FIGURE 8, the additional consumed helium is $3 \mathrm{~g} / \mathrm{s}$ or so at the inlet temperature of $4.8 \mathrm{~K}$. Therefore, to reduce the heat load along the helium passage as much as possible is helpful to lower the total mass flow rate and keep the dewar stable. The T-s diagram for the cavities' cooling is shown in FIGURE 9. TABLE 4 lists the operating parameters of the SRF cavities during normal operation.

TABLE 3. Estimated heat Load of the SRF cavities at 4.5 K[1]

\begin{tabular}{llc}
\hline \multirow{3}{*}{ Dynamic heat load } & Static heat load & $2 \times 30 \mathrm{~W}$ \\
& RF loss & $2 \times 72 \mathrm{~W}$ \\
Service Parts Heat Load & Coupler cooling & $2 \times 12 \mathrm{~W}$ \\
& Valve box & $20 \mathrm{~W}$ \\
& Transfer line & $24 \mathrm{~W}$ \\
& LHe dewar and heater & $30 \mathrm{~W}$ \\
\hline
\end{tabular}

TABLE 4. Operating parameters of the SRF cavities during normal operation

\begin{tabular}{lccccccc}
\hline & 0 & 1 & 4 & $8 \mathrm{~A}$ & $8 \mathrm{~B}$ & $9 \mathrm{~A}$ & $9 \mathrm{~B}$ \\
$\mathrm{P}($ bar $)$ & 13 & 1.23 & 1.2 & 1.22 & 1.22 & 1.22 & 1.22 \\
$\mathrm{~T}(\mathrm{~K})$ & 5.26 & 4.42 & 4.39 & 4.41 & 4.41 & 4.41 & 4.41 \\
$\mathrm{~m}(\mathrm{~g} / \mathrm{s})$ & 27.1 & 27.1 & 14.9 & 7.0 & 7.9 & 7.0 & 7.9 \\
Vapor fraction & 1 & 0.28 & 0 & 0.10 & 0.21 & 1 & 1 \\
& $13 \mathrm{~A}$ & $13 \mathrm{~B}$ & $3 \mathrm{~V}$ & 14 & & & \\
$\mathrm{P}($ bar $)$ & 1.2197 & 1.2195 & 1.217 & 1.20 & & & \\
$\mathrm{~T}(\mathrm{~K})$ & 4.41 & 4.41 & 4.86 & 4.39 & & & \\
$\mathrm{~m}(\mathrm{~g} / \mathrm{s})$ & 6.88 & 7.78 & 14.66 & 26.86 & & & \\
Vapor fraction & 1 & 1 & 1 & 1 & & & \\
\hline
\end{tabular}




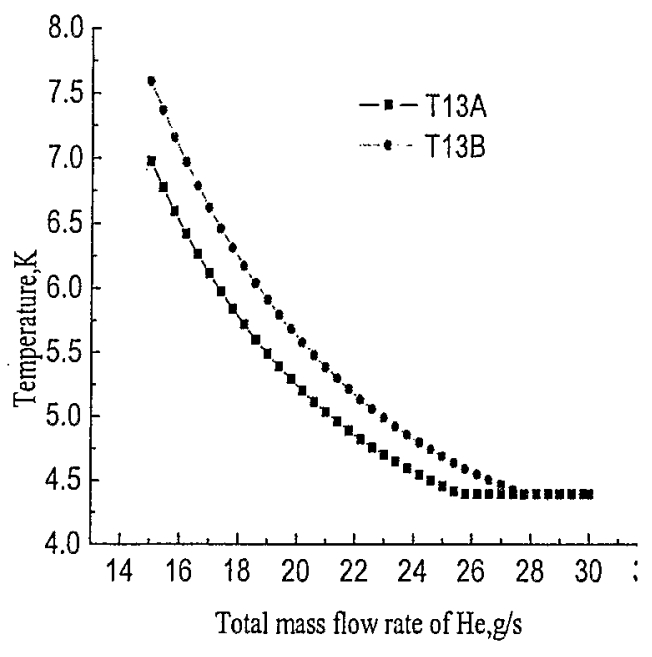

FIGURE 7. Total mass flow rate of he vs the temperature of return he at the outlet of valve box

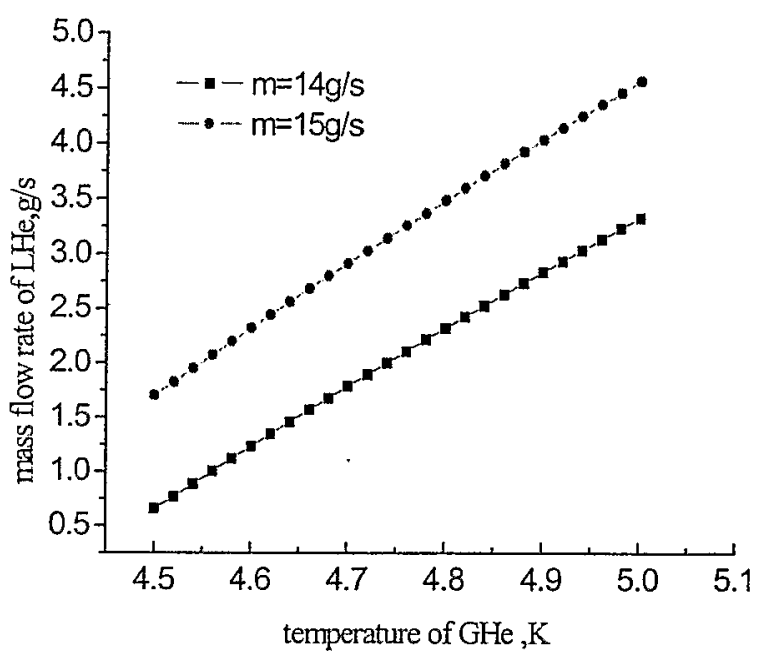

FIGURE 8. Additional consumed he vs the inlet temperature of gaseous he to the dewar

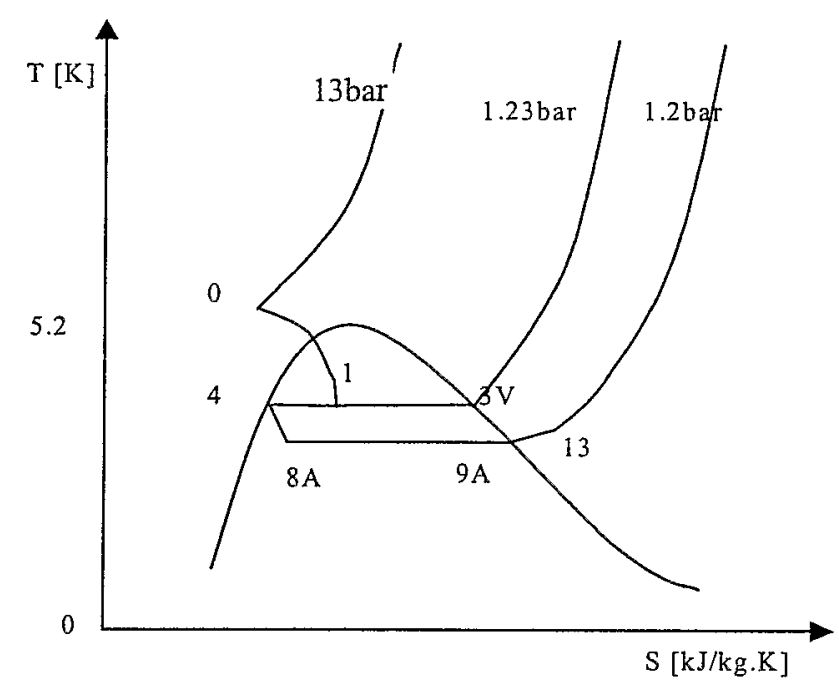

FIGURE 9. T-s diagram for the SRF cavity

\section{CONCLUSIONS}

The computational simulation of the cooling process for the BEPCII superconducting facilities based on the conceptual design for the BEPCII cryogenic system is carried out. The total mass flow rate of helium required by the SRF cryogenic system during normal operation state is $27.1 \mathrm{~g} / \mathrm{s}$. The total mass flow rate of helium required by the cryogenic system for the SCQ and SSM magnets is $36.03 \mathrm{~g} / \mathrm{s}$. Both of them are less than the mass flow rate of $41.28 \mathrm{~g} / \mathrm{s}$ supplied by the refrigerator. This indicates the cooling capacity of the 
refrigerators is enough for the BEPCII. The operating margins and parameters for the SRF, SCQ and SSM cooling systems are presented, respectively. The computational simulation will be further updated according to the developing engineering design.

*This work was performed under the auspices of U.S. Department of Energy, Contract No. DE-AC02-98CH10886.

\section{REFERENCES}

1. Conceptual Design Report of BEPCII Cryogenic System, Institute of Cryogenics and Superconductivity Technology, Harbin Institute of Technology, 2002.

2. Jia, L.X. and Wang, L., "Cryogenics in BEPCII Upgrade", The Proceedings of ICEC19, 2002.

3. Jia, L.X. and Wang, L., " $1 \mathrm{~kW}$ Cryoplant for BEPCII Superconducting Facilities", to be published in The Proceedings of ICCR2003, Hangzhou, China, 2002. 